\title{
Effects of Antidepressant Drugs on the Behavioral and Physiological Responses to Lipopolysaccharide (LPS) in Rodents
}

\author{
Raz Yirmiya, Ph.D., Yehuda Pollak, M.A., Ohr Barak, M.A., Ronit Avitsur, Ph.D., \\ Haim Ovadia, Ph.D., Michael Bette, Ph.D., Eberhard Weihe, M.D., and Joseph Weidenfeld, Ph.D.
}

Antidepressants produce various immunomodulatory effects, as well as an attenuation of the behavioral responses to immune challenges, such as lipopolysaccharide (LPS). To explore further the effects of antidepressants on neuroimmune interactions, rats were treated daily with either fluoxetine (Prozac) or saline for 5 weeks, and various behavioral, neuroendocrine, and immune functions were measured following administration of either LPS or saline. Chronic fluoxetine treatment significantly attenuated the anorexia and body weight loss, as well as the depletion of $\mathrm{CRH}-41$ from the median eminence and the elevation in serum corticosterone levels induced by LPS. Chronic treatment with imipramine also attenuated LPS-induced adrenocortical activation. In rats and in mice, which normally display a biphasic body temperature response to LPS (initial hypothermia followed by hyperthermia), chronic treatment with fluoxetine completely abolished the hypothermic response and facilitated and strengthened the hyperthermic response. The effects of antidepressants on the responsiveness to LPS are probably not mediated by their effects on peripheral proinflammatory cytokine production, because LPS-induced expression of TNF $\alpha$ and IL-1 $\beta$ $m R N A$ in the spleen (assessed by semiquantitative in situ hybridization) was not altered following chronic treatment with either fluoxetine or imipramine. The effects of antidepressants on the acute phase response may have important clinical implications for the psychiatric and neuroendocrine disturbances that are commonly associated with various medical conditions.

[Neuropsychopharmacology 24:531-544, 2001] (C) 2001 American College of Neuropsychopharmacology. Published by Elsevier Science Inc.
KEY WORDS: Fluoxetine (Prozac); Imipramine; Lipopolysaccharide (LPS); Tumor Necrosis Factor- $\alpha$ (TNF $\alpha)$; Interleukin-1 $\beta$ (IL-1 $\beta)$; Corticotrophin-releasing hormone (CRH); Corticosterone; Fever; Depression

From the Department of Psychology (RY, YP, OB, RA), The Hebrew University of Jerusalem, Mount Scopus, Jerusalem, Israel; Department of Neurology (HO, JW), Hadassah-Hebrew University Medical Center, Ein-Kerem, Jerusalem, Israel; Institute of Anatomy and Cell Biology, Department of Molecular Neuroimmunology (MB, EW), University of Marburg, Marburg, Germany

Address correspondence to: Raz Yirmiya, Ph.D., Department of Psychology, The Hebrew University of Jerusalem, Mount Scopus, Jerusalem 91905, Israel.

Received April 3, 2000; revised August 10, 2000; accepted September 8,2000 .
Several lines of evidence indicate that antidepressants produce various immunomodulatory effects. In depressed patients, the effects of antidepressants are variable and seem to be related to the immune status of the patients at the initiation of the treatment. When depression was associated with immune activation, antidepressants reduced immune function and cytokine secretion. For example, the increased plasma levels of IL-6 during acute depression were normalized by 8-week treatment with fluoxetine (Sluzewska et al. 1995), the increased monocyte counts in depressed patients were reduced following 6-weeks treatment with tricyclic antidepressants (TCAs) (Seidel et al. 1996), and the increased numbers of leukocytes and neutrophils were also reduced by antidepressant treatment (Maes et al. 
1997). On the other hand, when immune functions were found to be normal, antidepressants had no immunological effects; for example, chronic moclobemide treatment had no effect on monocytes functions, TNF $\alpha$ production or IFN $\gamma$ levels (Landmann et al. 1997). Moreover, in a study of depressed patients who exhibited immune suppression before treatment, the TCA clomipramine increased the production of IL-1 $\beta$, IL-2, and IL-3 (Weizman et al. 1994).

In experimental animals, TCAs as well as selective serotonin reuptake inhibitors (SSRIs) produce mainly immune suppression and anti-inflammatory effects. For example, antidepressant treatment in vivo inhibited the increased acute phase response in olfactory bulbectomized rats, a useful animal model of depression (Song and Leonard 1994), reduced the production of interleukin-1 (IL-1) and IL-2 in a chronic mild stress model of depression (Kubera et al. 1996), inhibited immune activation in rats with experimental allergic neuritis (Zhu et al. 1994), and produced anti-inflammatory effects in carrageenin- or brewer's yeast-induced inflammation (Bianchi et al. 1994, 1995; Michelson et al. 1994).

In addition to their effects on immune functions, antidepressants were also found to attenuate the behavioral effects of immune activation. We have previously reported that treatment with the TCA imipramine attenuated the depressive-like behavioral syndrome that is induced in rats by administration of the immune activator lipopolysaccharide (LPS) (Yirmiya 1996, 1997). Specifically, chronic (5 weeks of daily injections), but not acute administration of imipramine attenuated LPS-induced decrease in the consumption of and preference for saccharine solution, which is considered as a good animal model of anhedonia (Willner 1997), as well as other sickness behavior symptoms, including anorexia, weight loss, and reduced social, locomotor, and exploratory behavior (Yirmiya 1996). Similar findings were recently reported using chronic treatment with the TCA desipramine. However, in that study, treatment with paroxetine and venlafaxine (selective reuptake inhibitors of serotonin and norepinephrine, respectively) did not attenuate LPS-induced sickness behavior (Shen et al. 1999). One aim of the present study was to extend these findings by examining the effects of the SSRI fluoxetine (Prozac) on LPS-induced sickness behavior. Because LPS also produces marked changes in body temperature and activation of the hypothalamus-pituitary-adrenal (HPA) axis (Kluger 1991; Tilders et al. 1994), another aim of the present study was to examine the effects of antidepressant treatment on these thermoregulatory and neuroendocrine components of the acute phase response.

Some of the effects of antidepressants are probably mediated by a direct action on immune cells. For example, TCAs were found to inhibit spontaneous secretion of IL-2 and IFN $\gamma$ from T-cells, as well as spontaneous and LPS-induced secretion of IL-1 $\beta$, IL- 6 and TNF $\alpha$ from monocytes (Xia et al. 1996). Similarly, the antidepressant rolipram was found to suppress TNF $\alpha$ and (to a lesser extent) also IFN $\gamma$ secretion by human and rat auto-reactive T-cells (Sommer et al. 1995). Finally, in a recent study, exposure to antidepressants not only suppressed stimulated IFN $\gamma$ secretion, but also increased the secretion of IL-10, suggesting a general negative immunoregulatory effect (Maes et al. 1999). All of these studies were conducted using acute in vitro exposure to antidepressants, and, therefore, their relevance to the effects of antidepressants on LPS-induced sickness behavior is questionable. As a first attempt to determine whether the effects of chronic antidepressant treatment on the behavioral and neuroendocrine responses to LPS are mediated by suppression of LPS-induced activation of cytokine systems, we measured the effects of chronic treatment with both fluoxetine and imipramine on the induction of TNF $\alpha$ and IL-1 $\beta$ mRNA following LPS administration in vivo.

\section{METHODS}

\section{Subjects}

Subjects were Fischer 344 male rats or male SJL mice, 10-12 weeks-old (Harlan-Sprague-Dawley, Jerusalem). The study was approved by the Hebrew University Committee for Experimentation on Laboratory Animals. Rats and mice were housed three/cage and five/ cage, respectively, in an air-conditioned room (23 \pm $1^{\circ} \mathrm{C}$ ), with food and water ad libitum for several weeks before the beginning of the experiment, as well as during the first 3-5 weeks of chronic drug administration (see below). Experimental manipulations (injections and initial measurements) started at the beginning of the dark phase of a reversed 12-h light/dark cycle.

\section{PROCEDURE}

\section{Experiment 1: Effects of Chronic Treatment with Fluoxetine on LPS-Induced Sickness Behavior}

At the beginning of the experiment, rats were divided into two groups receiving a daily IP injection of either saline or fluoxetine (Prozac; $10 \mathrm{mg} / \mathrm{kg}$ ) (Eli Lilly and Company, USA) for 5 weeks. This dose was chosen, because in several previous studies it was shown to attenuate the behavioral and neuroendocrine effects of acute challenges (e.g., Li et al. 1993; Zhang et al. 2000). Rats were weighed weekly. One week before the experiment, animals were separated into individual cages. Two days before the experiment, baseline food consumption was measured by giving each rat $100.0 \mathrm{~g}$ of food pellets and weighing the remaining food $24 \mathrm{~h}$ later. Preliminary experiments showed that food spillage was negligible (less than $1 \%$ of the food consumed). 
One day before the experiment, rats within the saline and fluoxetine groups were divided into two subgroups $(n=9-10)$, matched for mean food consumption and body weight.

On the morning of the behavioral experiment day, rats were weighed and injected with either saline or fluoxetine, as before, followed immediately by an IP injection of either saline or LPS $(100 \mu \mathrm{g} / \mathrm{kg})$ (E. Coli 055, Difco Laboratories, Detroit, MI). This dose of LPS induces robust sickness behavior, which was previously found to be attenuated by chronic treatment with imipramine (Yirmiya 1996). Immediately following the second injection, food was replaced with $100.0 \mathrm{~g}$ of fresh pellets for measurement of food consumption. Activity in the open field test was assessed $4 \mathrm{~h}$ after the injections, in a dimly illuminated, quite room. Each rat was placed in the corner of an open field $(95 \times 95 \times 60 \mathrm{~cm})$ divided into 25 identical squares. The incidences of line crossing with both hind paws and rearing were recorded by an observer blind to the treatment received by the animal, over a period of $3 \mathrm{~min}$. Body weight and food consumption were measured $24 \mathrm{~h}$ after the injection. The results were analyzed by two-way analyses of variance (ANOVAs), followed by post-hoc tests with the Fisher PLSD procedure $(p<.05)$.

\section{Experiment 2: Effects of Chronic Antidepressant Treatment on LPS-Induced Activation of the Hypothalamic-Pituitary-Adrenal Axis}

Following chronic treatment (daily IP injections for 5 weeks) with either fluoxetine $(10 \mathrm{mg} / \mathrm{kg})$ or saline, rats within each group were divided into two subgroups $(n=$ 8-9), matched for mean body weight. Animals were transferred to individual cages $24 \mathrm{~h}$ before the experiment, to avoid the acute stress associated with taking out individual rats from a group cage during the sacrifice procedure (in preliminary experiments, we found that if animals are taken out, one by one, from a group cage, the last animals have higher corticosterone levels than the first ones). On the experiment day, rats received either saline or fluoxetine, as before, followed by an injection of either saline or LPS $(50 \mu \mathrm{g} / \mathrm{kg})$. We used an LPS dose that was lower than the one used for the behavioral studies, because the HPA axis is more sensitive to LPS than behavioral systems (e.g., Johnson et al. 1996), and the use of a higher dose could interfere with the ability to demonstrate fluoxetine-induced attenuation of the HPA response. Two h later, rats were decapitated, the brains were removed, and immediately placed on ice. The median eminence (ME) was uniformly excised under a binocular and was placed in 500 $\mu \mathrm{l}$ ice-cold $0.1 \mathrm{M} \mathrm{HCl}$. The tissue was stored at $-80^{\circ} \mathrm{C}$ until assayed for immunoreactive CRH-41 ME content. Trunk blood was collected, and serum samples were also stored at $-80^{\circ} \mathrm{C}$ for subsequent corticosterone determination.
The content of immunoreactive CRH-41 in the ME was measured in tissue extracts by RIA, using a specific anti-CRH-41 antiserum obtained from the Pasteur Institute (Paris). The tissues were homogenized by ultrasonic disruption for $20 \mathrm{~s}$. Following $15 \mathrm{~min}$ centrifugation at $10,000 \mathrm{rpm}$, at $4^{\circ} \mathrm{C}$, duplicated $10-\mu \mathrm{l}$ aliquots were removed into plastic tubes containing $10 \mu 10.5 \mathrm{M}$ potassium phosphate buffer, $\mathrm{pH} 7.4$, and $80 \mu \mathrm{l}$ of assay buffer was then added. Assay tubes were incubated for $72 \mathrm{~h}$ at $4^{\circ} \mathrm{C}$ with $0.1 \mathrm{ml}$ of anti-CRH-41 (dilution $1: 12,500)$. Tubes were then incubated for an additional $72 \mathrm{~h}$ with ${ }^{125} \mathrm{I}$-labled Tyr-CRH-41. To stop the reaction, $100 \mu \mathrm{l}$ normal rabbit serum (diluted 1:80 in saline) was added, followed by $100 \mu \mathrm{l}$ horse serum anti-rabbit globulin (dilution 1:75) and $1 \mathrm{ml}$ of $6 \%$ polyethylene glycol dissolved in water. Samples were vortexed and incubated for $45 \mathrm{~min}$ in an ice-cold water bath. Tubes were then centrifuged at $4000 \mathrm{rpm}, 4^{\circ} \mathrm{C}$, for $20 \mathrm{~min}$. The supernatant was aspirated, and the pellet was counted in a gamma counter. The sensitivity limit of this assay is 3 $\mathrm{pg} /$ tube and the intra- and interassay coefficients of variation are $5.8 \%$ and $6.5 \%$, respectively. The content of CRH-41 determined was directly proportional to different dilutions of volumes taken $(2-10 \mu \mathrm{l})$ from the tissue extracts. Serum corticosterone was determined by radioimmunoassay (RIA), as previously described (Weidenfeld and Yirmiya 1996). The sensitivity limit of the assay is $0.5 \mu \mathrm{g} / 100 \mathrm{ml}$, and the intra- and interassay coefficients of variation were 6.3 and $7 \%$, respectively.

To further explore the generality of the effects of antidepressants on the adrenocortical activation we conducted a second study, examining the effects of both fluoxetine and imipramine on corticosterone secretion following a higher dose of LPS (the dose used in the behavioral testing). Rats received a daily injection (IP) of either saline, imipramine $(10 \mathrm{mg} / \mathrm{kg})$ or fluoxetine $(10$ $\mathrm{mg} / \mathrm{kg}$ ) for 5 weeks. On the experiment day, rats were weighed and injected with either saline or fluoxetine, as before, followed immediately by an injection of either saline or LPS $(100 \mu \mathrm{g} / \mathrm{kg})$. Two h later, rats were sacrificed by decapitation, and trunk blood was collected for corticosterone determination. Serum corticosterone was determined as described above.

The results of both experiments were analyzed by two-way analyses of variance (ANOVAs), followed by post-hoc tests with the Fisher PLSD procedure $(p<.05)$.

\section{Experiment 3: Effects of Acute Fluoxetine Treatment on LPS-Induced Sickness Behavior and Corticosterone Secretion}

To assess the effects of acute fluoxetine administration on sickness behavior, rats were divided into four groups $(n=6-7)$, matched for mean baseline food consumption and body weight (see procedure for Experiment 1). On the morning of the behavioral experiment day, rats were injected IP with either saline or fluoxetine $(10 \mathrm{mg} / \mathrm{kg})$, 
followed immediately by an IP injection of either saline or LPS $(100 \mu \mathrm{g} / \mathrm{kg})$. Food consumption, changes in body weight, and open field activity were measured, as described in the procedure for Experiment 1.

To assess the effects of acute fluoxetine administration on corticosterone secretion, a different group of rats was divided to four subgroups $(n=6-8)$, injected acutely with either saline or fluoxetine followed by either saline or LPS, as described above. Two $h$ after the injections, rats were sacrificed and serum corticosterone levels were assessed as described in the procedure for Experiment 2.

The results of both experiments were analyzed by two-way ANOVAs, followed by post-hoc tests with the Fisher PLSD procedure $(p<.05)$.

\section{Experiment 4: Effects of Chronic Fluoxetine Treatment on LPS-Induced Changes in Body Temperature}

Rats were divided into two groups receiving a daily IP injection of either saline or fluoxetine $(10 \mathrm{mg} / \mathrm{kg})$ for 5 weeks. Rats were weighed weekly. Two weeks following the initiation of this treatment, rats were implanted with biotelemetric transmitters (model VM-FH, Mini Mitter Co. Inc., Sunriver, OR) into the peritoneal cavity, as previously described (Yirmiya et al. 1997), and transferred into individual cages. Following 5 weeks of the chronic treatment, each animal's cage was placed over a receiver board (model RA-1010, Mini Mitter Co. Inc., Sunriver, OR), whose output was fed into a peripheral processor (BCM100) connected to a personal computer. Baseline body temperature was recorded for 3 days. On the morning of the experiment day, rats within the saline and fluoxetine groups were divided into two subgroups $(n=6)$, injected IP with either saline or LPS (100 $\mu \mathrm{g} / \mathrm{kg}$ ), and body temperature was recorded for an additional $24 \mathrm{~h}$, at 30-min intervals.

The results were analyzed by a two-way ANOVA, with the chronic (saline vs. fluoxetine) and acute (saline vs. LPS) treatments as between-group factors, and the time as a within-subjects, repeated measures factor. Because LPS produced a biphasic effect on body temperature (initial hypothermia followed by prolonged hyperthermia) the results of each phase were analyzed separately.

To extend the findings with rats, we conducted a second experiment on the effects of chronic fluoxetine treatment on LPS-induced body temperature changes in mice. Male SJL mice were divided into two groups $(n=$ 8), injected IP daily with either saline or fluoxetine (10 $\mathrm{mg} / \mathrm{kg}$ in a volume of $10 \mathrm{ml} / \mathrm{kg}$ ). Two weeks following the initiation of this treatment, mice were implanted with biotelemetric transmitters, as described above. Following 5 weeks of the chronic treatment, each animal's cage was placed over a receiver board, and baseline body temperature was recorded for 3 days. On the morning of the experiment day, at the beginning of the light period, mice were injected IP with LPS $(50 \mu \mathrm{g} / \mathrm{kg})$.
We used a lower dose of LPS than the one used in rats, because in preliminary experiments, we found that SJL mice are more sensitive than rats to many of the behavioral effects of LPS. Body temperature was recorded for an additional $24 \mathrm{hr}$, at 30-min intervals.

The results were analyzed by a two-way ANOVA, with the group as a between- subjects factor and the measurement times as within-subjects, repeated measure factor.

\section{Experiment 5: Effects of Chronic Antidepressant Treatment on LPS-Induced Splenic Cytokine Expression}

Rats were divided into three groups, injected IP daily with either saline, imipramine $(10 \mathrm{mg} / \mathrm{kg})$ or fluoxetine $(10 \mathrm{mg} / \mathrm{kg})$ for 5 weeks. On the experiment day, rats within each group were injected with their respective drug, and were then divided into subgroups, injected IP with either saline or LPS $(100 \mu \mathrm{g} / \mathrm{kg})$. Three hours following the injection, rats were sacrificed, and spleens were rapidly removed and placed in temperature controlled isopentane $\left(-30--50^{\circ} \mathrm{C}\right)$ for $15-30 \mathrm{~s}$. Tissues were then frozen in dry ice, wrapped in parafilm, and transferred to a $-80^{\circ} \mathrm{C}$ freezer for storage.

For in situ hybridization, rat specific cDNA fragments were generated by reverse transcription PCR of total RNA from rat lymph node. For IL- $1 \beta$ cDNA, a 589 bp fragment ranging from bp 206 to bp 795 of IL-1 $\beta$ cRNA (Acc. M98820) and for TNF $\alpha$ cDNA a $291 \mathrm{bp}$ fragment ranging from bp 4432 within Exon 1 to bp 5348 within Exon 3 of TNF $\alpha$ DNA (Acc. L00981) were amplified and inserted into a pGEM-T vector (Promega, Germany). IL-1 $\beta$ cDNA was linearized with Not I or Nco I, TNF $\alpha$ cDNA was linearized with Apa I or Pst I restriction enzymes (Boehringer Mannheim, Germany). 35S-labeled sense and antisense riboprobes were generated by in vitro transcription using SP6 or T7 polymerases (Boehringer Mannheim, Germany) as appropriate in the presence of 35S-UTP (Amersham Life Science, Germany). All labeled cRNAs were purified over NucTrap purification columns (Stratagene, Germany) and diluted in hybridization-buffer $(100 \mathrm{mM}$ Tris pH 7.5, $600 \mathrm{mM} \mathrm{NaCl}, 1 \mathrm{mM}$ EDTA, $0.5 \mathrm{mg} / \mathrm{ml}$ $\mathrm{t}-\mathrm{RNA}, 0.1 \mathrm{mg} / \mathrm{ml}$ sonicated salmon sperm DNA, $1 \mathrm{x}$ Denhardt's, $10 \%$ dextrane sulfate, $50 \%$ formamide) to $50,000 \mathrm{cpm} / \mu \mathrm{l}$. Labeled cRNA was stored for no longer than 3 weeks at $-75^{\circ} \mathrm{C}$. In situ hybridization was performed in nine serial cryostat sections $(20 \mu \mathrm{m})$ from each animal. Tissue sections were fixed in $4 \%$ paraformaldehyde in PBS at $4^{\circ} \mathrm{C}$ for $1 \mathrm{~h}$, washed three times in PBS, penetrated by $0.4 \%$ Triton X-100 in PBS for $5 \mathrm{~min}$ and acetylated for $10 \mathrm{~min}$ in $0.1 \mathrm{M}$ triethanolamine $\mathrm{pH}$ 8.0 with $0.25 \%$ acetic anhydride. Tissues were washed in $2 x$ SSC, dehydrated in ethanol and stored at $-20^{\circ} \mathrm{C}$ until hybridization. Hybridization with cRNA, prepared by in vitro transcription, was performed by incu- 
bation of $35 \mu l$ of cRNA on tissue sections for $16-18 \mathrm{~h}$ at $56^{\circ} \mathrm{C}$ in a moist chamber. Sections were washed in $2 x$ SSC and $1 \times$ SSC for $10 \mathrm{~min}$ each, and single stranded RNA was digested by $10 \mu \mathrm{g} / \mathrm{ml}$ RNAse and $1 \mathrm{U} / \mathrm{ml} \mathrm{T1}$ RNAse (Boehringer Mannheim) in Tris/EDTA pH 8.0, $150 \mathrm{mM} \mathrm{NaCl}$ at $37^{\circ} \mathrm{C}$ for $1 \mathrm{~h}$. Afterward, sections were desalted by passing them through $1 \mathrm{x}$ SSC, $0.5 \mathrm{x}$ SSC, $0.2 x$ SSC for $10 \mathrm{~min}$ each and washed in $0.2 x$ SSC at $60^{\circ} \mathrm{C}$ for $1 \mathrm{~h}$. Then the tissue sections were washed in $\mathrm{H}_{2} \mathrm{O}$ for $10 \mathrm{~min}$, dehydrated by ethanol and air dried. Autoradiograms were taken by exposing the sections to an autoradiography film (Hyperfilm- $\beta$ max, Amersham, Dreieich, Germany) for 1-3 days. For quantification, radioactive standards were exposed simultaneously to the autoradiograms. Digital image analysis of the autoradiograms was performed using the NIH Image program. The data from the sections for each animal was averaged, and the results were analyzed by two-way
ANOVAs, followed by post-hoc tests with the Fisher PLSD procedure $(p<.05)$.

\section{RESULTS}

\section{Experiment 1: Effects of Chronic Treatment with Fluoxetine on LPS-Induced Sickness Behavior}

Chronic treatment with fluoxetine was associated with a reduction in food consumption and body weight. At baseline (i.e., following 5 weeks of fluoxetine administration), 24-h food consumption in saline- and fluoxetinetreated rats was 19.7 and $16.2 \mathrm{~g}$, respectively $[\mathrm{t}(34)=4.62$, $p<.001]$. Body weight in saline- and fluoxetine-treated rats was 331 and $276 \mathrm{~g}$, respectively [(34) $=5.62, p<.001]$.

LPS produced a significant over-all reduction in food consumption $[\mathrm{F}(1,32)=47.64, p<.0001]$ (Figure 1A). A significant interaction was found between the chronic
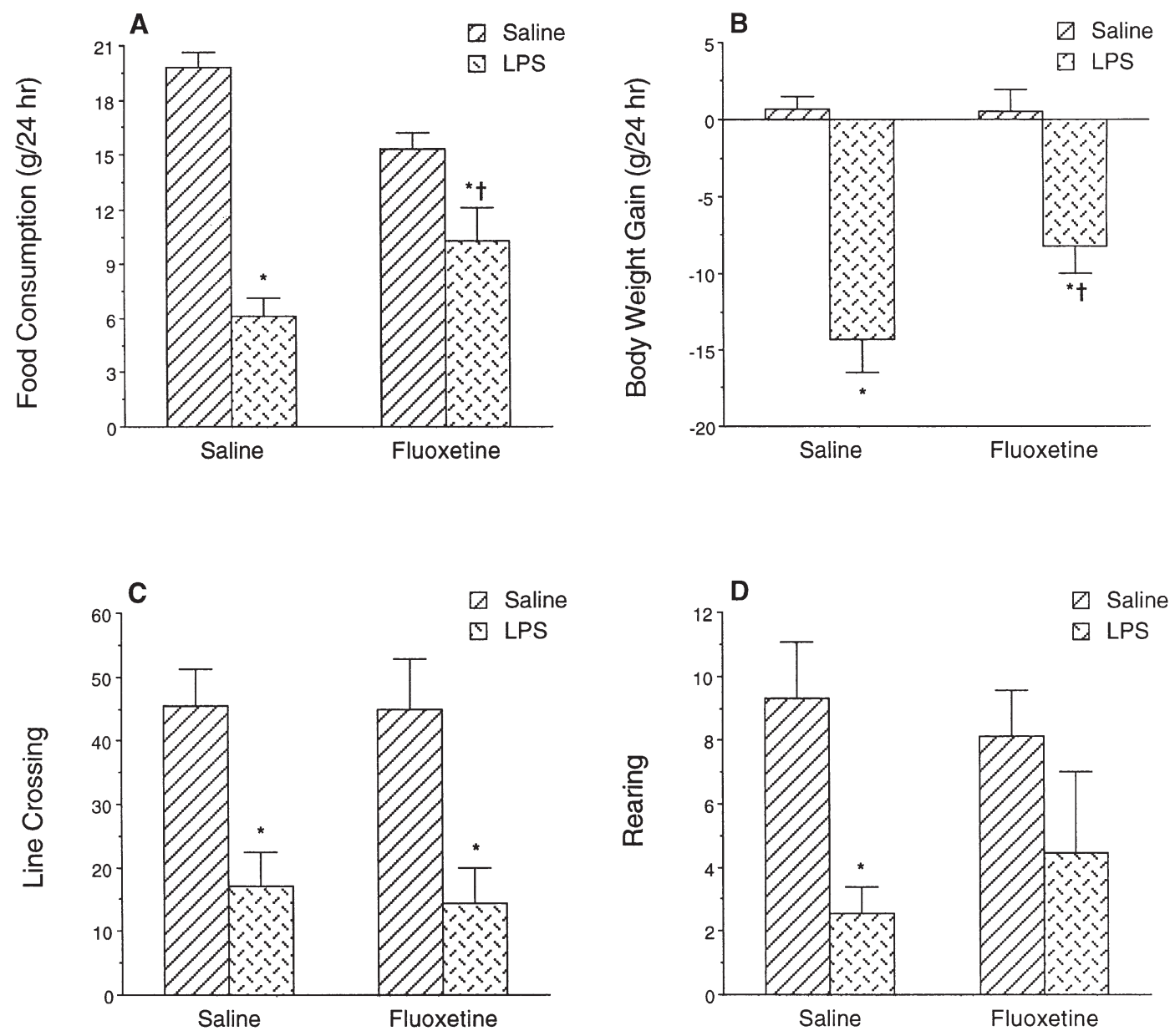

Figure 1. Effects of chronic treatment with fluoxetine on LPS-induced decrease in food consumption, body weight, and open field activity. Following chronic treatment with either saline or fluoxetine $(10 \mathrm{mg} / \mathrm{kg}$, injected IP daily for $5 \mathrm{weeks})$, rats were injected acutely with either saline or LPS $(100 \mu \mathrm{g} / \mathrm{kg})(n=8-10$ rats/group). A: Mean ( \pm S.E.M.) food consumption $(\mathrm{g} / 24 \mathrm{~h})$, measured $24 \mathrm{~h}$ following the acute injection. B: Mean $( \pm \mathrm{SEM})$ body weight gain $(\mathrm{g} / 24 \mathrm{~h}), 24 \mathrm{~h}$ following the acute injection. C and D: Mean ( \pm S.E.M.) line crossing and rearing in the open field test, measured $4 \mathrm{~h}$ after the administration of either LPS or saline. *Significantly different from the corresponding acutely injected saline group $(p<.05)$. ${ }^{\dagger}$ Significantly different from LPS-injected rats treated chronically with saline $(p<.05)$. 
(fluoxetine/saline) and acute (LPS/saline) injections $[\mathrm{F}(1,32)=4.16, p<.05]$, reflecting the greater decrease in food consumption in LPS-injected rats chronically treated with saline compared to fluoxetine-treated rats. Post-hoc analysis showed that LPS produced significant anorexia in both chronic treatment groups; however, LPS-induced reduction in food consumption was significantly smaller in fluoxetine- than in saline-treated rats.

LPS produced a significant over-all reduction in body weight (bw) $[\mathrm{F}(1,32=58.21, p<.0001]$ (Figure 1B). A significant interaction was found between the chronic (fluoxetine/saline) and acute (LPS/saline) injections $[\mathrm{F}(1,32)$ $=4.15, p<.05]$, reflecting the greater decrease in bw in LPS-injected rats chronically treated with saline as compared to fluoxetine-treated rats. Post-hoc analysis showed that LPS significantly reduced bw in both chronic treatment groups, however, LPS-induced reduction in bw was significantly smaller in fluoxetine- than in saline-treated rats. Because the chronic fluoxetine and saline treatment groups differed markedly in baseline bw, a similar analysis was conducted on the absolute values (i.e., ANOVA with repeated measures on the values at baseline and 24-h post sal/LPS injection). The same pattern of results was obtained in this analysis.

LPS significantly decreased line crossing and rearing in the open field test $[\mathrm{F}(1,33)=22.36$, and 8.60, respectively, $p<.005$ ) (Figure $1 \mathrm{C}$ and D). There were no significant interactions between the chronic (fluoxetine/ saline) and the acute (LPS/saline) treatments.

\section{Experiment 2: Effects of Chronic Fluoxetine Treatment on LPS-Induced Activation of the HPA Axis}

Administration of LPS produced a pronounced depletion of CRH-41 ME content $(40 \%)$ with a concomitant 4 -fold increase in serum corticosterone in rats that were chronically injected with saline (Figures 2A and B). Chronic treatment with fluoxetine completely abolished the neuroendocrine effects of LPS. These findings were reflected by significant interactions between the chronic (saline/ fluoxetine) and the acute (saline/LPS) treatments, with respect to both CRH-41 ME content and corticosterone secretion $[\mathrm{F}(1,29)=4.31$ and 4.20 , respectively, $p<.05]$.

In the second experiment, treatment with both imipramine and fluoxetine were found to attenuate the effects of LPS on serum corticosterone levels, reflected by a significant interaction between the chronic (saline/ fluoxetine/imipramine) and acute (saline/LPS) treatments $[F(2,24)=9.3, p<.001]$ (Figure 3). Post-hoc tests revealed that LPS induced a significant elevation in corticosterone levels in rats treated chronically with saline or imipramine, but not with fluoxetine. Furthermore, LPS-injected rats treated with either imipramine or fluoxetine had significantly lower corticosterone levels than LPS-injected rats treated chronically with saline.
Body weight in the fluoxetine and imipramine treatment groups was $18 \%$ and $5 \%$, respectively, lower than in the control group. However, there was no correlation between body weight and corticosterone secretion in either the saline or the LPS groups $(p<.2)$.

\section{Experiment 3: Effects of Acute Fluoxetine Treatment on LPS-Induced Sickness Behavior and Corticosterone Secretion}

Acute injections with both fluoxetine and LPS produced a significant reduction in food consumption $[\mathrm{F}(1,22)=31.25$ and 29.11, respectively, $p<.001]$ (Figure $4 \mathrm{~A})$. A significant interaction was found between the first (fluoxetine/saline) and second (LPS/saline) injection $[\mathrm{F}(1,22)=8.38, p<.05]$. Post-hoc analysis showed that both LPS and fluoxetine produced significant anorexia. There was no significant difference between the two LPS-injected groups.

Both fluoxetine and LPS produced a significant reduction in body weight gain $[\mathrm{F}(1,32=5.43$ and 32.8 , respectively, $p<.05$ ] (Figure 4B); however, the interaction between the first and second injection did not reach statistical significance. Post-hoc analysis showed that LPS significantly reduced body weight in rats injected with either saline or fluoxetine. There was no significant difference between the two LPS-injected groups.

Both fluoxetine and LPS significantly decreased line crossing $[\mathrm{F}(1,22)=35.02$ and 33.08 , respectively, $p<$ $.001]$ and rearing $[\mathrm{F}(1,22)=7.29$ and 16.96 , respectively, $p<.01$ ] (Figure $4 \mathrm{C}$ and D) in the open field test. In line crossing, but not in rearing, a significant interaction was found between the first (fluoxetine/saline) and second (LPS/saline) injection $[\mathrm{F}(1,22)=15.30, p<.005]$. Post-hoc analysis showed that both LPS and fluoxetine produced a significant decrease in line crossing and rearing. There were no significant differences between the two LPS-injected groups.

Both fluoxetine and LPS significantly elevated serum corticosterone levels $[\mathrm{F}(1,23)=13.88$ and 10.02 , respectively, $p<.01$ ] (Figure 4E). A significant interaction was found between the first (fluoxetine/saline) and second (LPS/saline) injection $[\mathrm{F}(1,22)=6.28, p<.05]$. Post-hoc analysis showed that both LPS and fluoxetine produced a significant increase in corticosterone levels. There was no significant difference between the two LPS-injected groups.

\section{Experiment 4: Effects of Chronic Fluoxetine Treatment on LPS-Induced Changes in Body Temperature}

At baseline, there were no differences in body temperature between rats that were treated chronically with fluoxetine or saline. In rats that were chronically treated with saline, LPS produced a biphasic change in body temperature, with initial hypothermia at $2-6 \mathrm{~h}$ postinjec- 

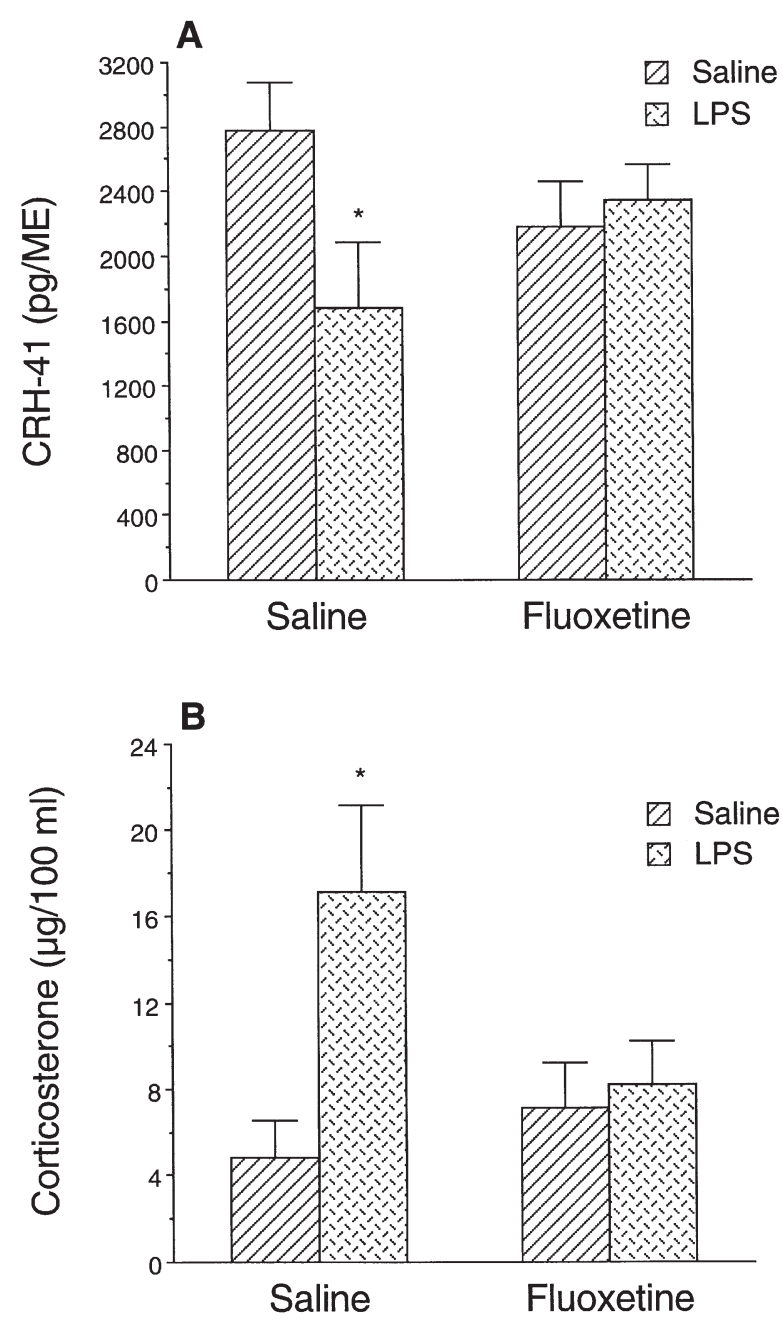

Figure 2. Effects of chronic treatment with fluoxetine on LPS-induced activation of the HPA axis. Following chronic treatment with either saline or fluoxetine $(10 \mathrm{mg} / \mathrm{kg}$, injected IP daily for 5 weeks), rats were injected acutely with either saline or LPS (50 $\mu \mathrm{g} / \mathrm{kg})(n=8-9$ rats/group). Two $\mathrm{h}$ later, rats were sacrificed, the ME was uniformly excised for later determination of the content of immunoreactive CRH41 , and blood was collected for subsequent corticosterone determination. A: Mean ( \pm S.E.M.) levels of CRH-41 (pg/ Median Eminence). B: Mean ( \pm S.E.M.) serum corticosterone levels $(\mu \mathrm{g} / 100 \mathrm{ml})$. *Significantly different from the corresponding acutely injected saline group $(p<.05)$.

tion, followed by prolonged hyperthermia, at 12-23 $\mathrm{h}$ postinjection (Figure 5A). Chronic fluoxetine treatment completely abolished the hypothermic response to LPS and altered the kinetics of the hyperthermic response. Thus, fluoxetine-treated rats displayed only LPS-induced hyperthermia, which began at $3 \mathrm{~h}$ postinjection and continued throughout the measurement period, with a slight reduction below the control levels at 17-23 $h$ postinjection. These effects were reflected by a significant interaction between the first (fluoxetine/saline) and second (LPS/saline) injection during the hypothermic

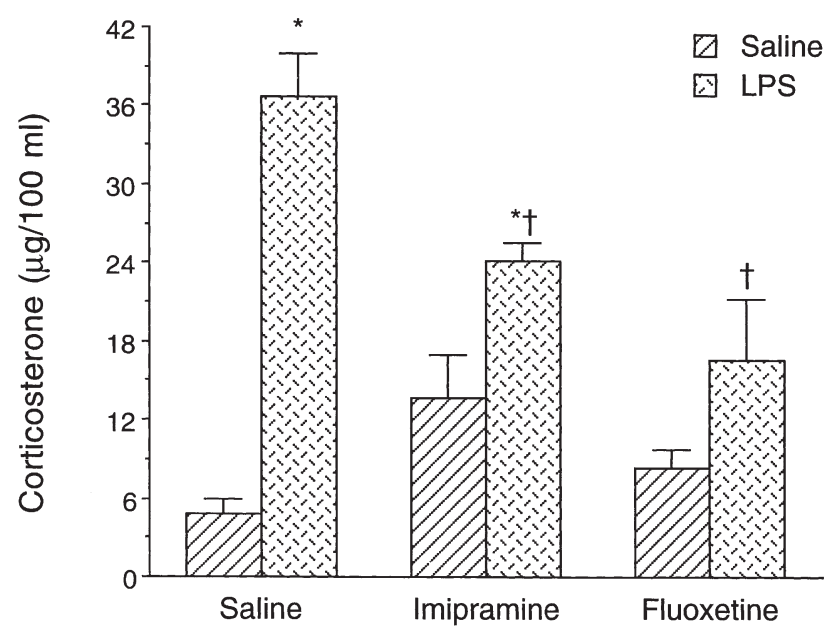

Figure 3. Effects of chronic treatment with fluoxetine or imipramine on LPS-induced adrenocortical activation. Following chronic treatment (daily IP injections for 5 weeks) with saline, imipramine $(10 \mathrm{mg} / \mathrm{kg})$ or fluoxetine $(10 \mathrm{mg} /$ $\mathrm{kg})$, rats were injected acutely with either saline or LPS (100 $\mu \mathrm{g} / \mathrm{kg})$. Serum corticosterone levels $(\mu \mathrm{g} / 100 \mathrm{ml})$ were measured $2 \mathrm{~h}$ following the acute injection. The results represent the mean ( \pm S.E.M.) of 5-7 rats/group. *Significantly different from the corresponding acutely injected saline group ( $p$ $<$.05). ${ }^{+}$Significantly different from LPS-injected rats treated chronically with saline $(p<.05)$.

phase $[F(1,19)=8.56, p<.005]$, and a significant first injection by second injection by time interaction during the hyperthermic phase $[\mathrm{F}(33,627)=2.96, p<.001]$.

In mice that were chronically treated with saline, LPS also produced a biphasic change in body temperature, with initial hypothermia at $1.5-3.5 \mathrm{~h}$ postinjection, followed by hyperthermia, at $4.5-9 \mathrm{~h}$ postinjection (Figure 5B). Chronic fluoxetine treatment completely abolished the hypothermic response to LPS. Thus, fluoxetine-treated mice displayed only LPS-induced hyperthermia, which began $3 \mathrm{~h}$ postinjection and subsided by $9 \mathrm{~h}$ postinjection. These effects were reflected by a significant effect of fluoxetine during the hypothermic phase $[\mathrm{F}(1,14)=5.44, p<.05]$, and a similar trend, which did not reach statistical significance, during the hyperthermic phase $[\mathrm{F}(1,14)=3.69, p=.07]$.

\section{Experiment 5: Effects of Chronic Antidepressant Treatment on LPS-Induced Splenic Cytokine Expression}

LPS produced a marked increase in the expression of TNF $\alpha$ and IL-1 $\beta$ mRNA $[F(1,35)=82.2$ and 90.4, respectively, $p<.0001]$, which was not influenced by the antidepressant treatment (Figures 6 and 7). Post-hoc analysis revealed that the difference between the LPS and saline subgroups was significant in all chronic treatment groups. Neither fluoxetine nor imipramine had any effect on LPS-induced TNF $\alpha$ or IL-1 $\beta$ expression. 

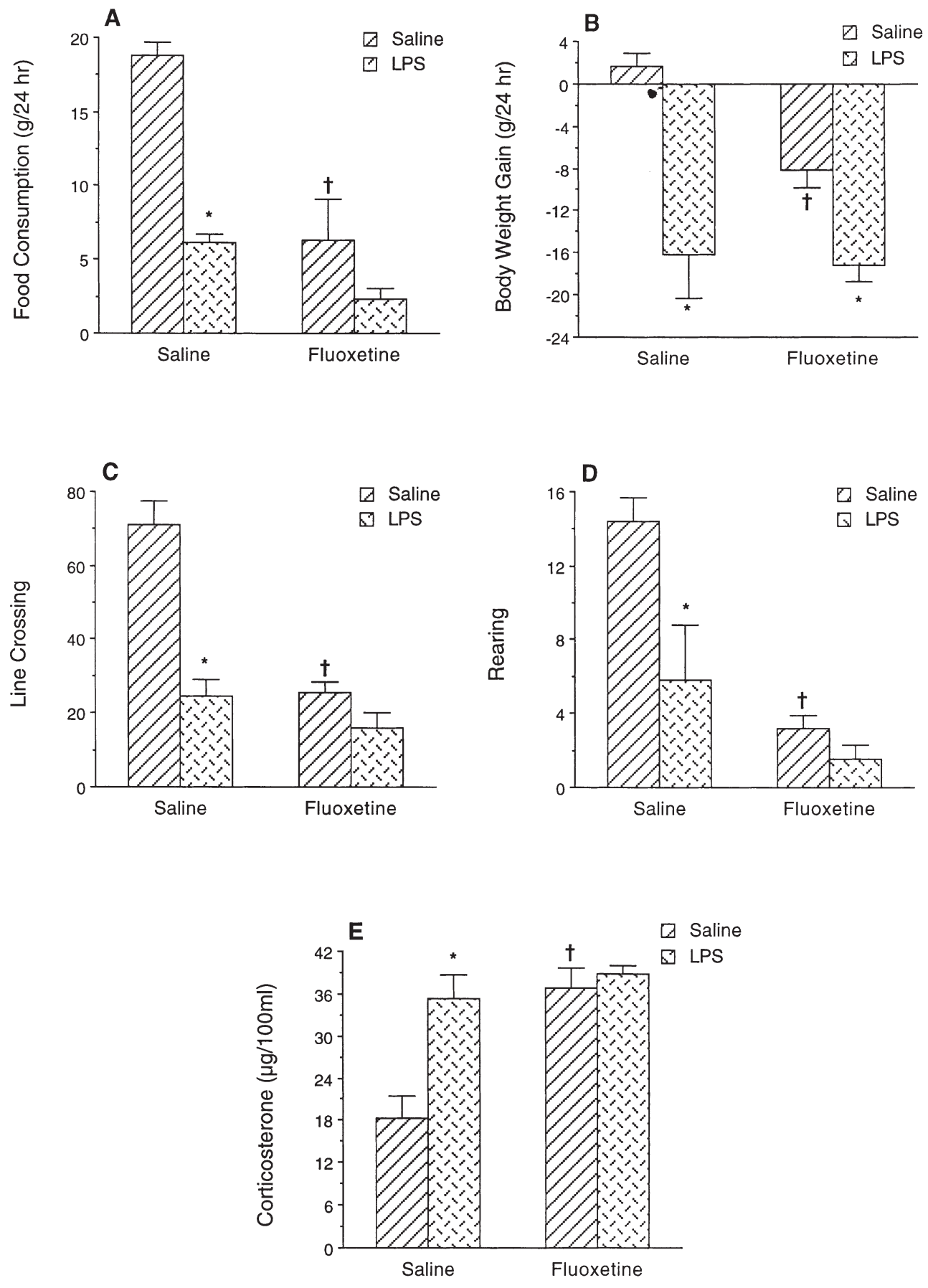

Figure 4. Effects of acute treatment with fluoxetine on LPS-induced changes in food consumption, body weight, open field activity, and corticosterone secretion. Following acute IP injection with either saline or fluoxetine $(10 \mathrm{mg} / \mathrm{kg})$, rats were injected with either saline or LPS $(100 \mu \mathrm{g} / \mathrm{kg})(n=6-7$ rats/group in the behavioral experiment and 6-8 rats/group in the corticosterone experiment). A. Mean ( \pm S.E.M.) food consumption (g/24 h), measured $24 \mathrm{~h}$ following the injections. B. Mean ( \pm SEM) body-weight gain $(\mathrm{g} / 24 \mathrm{~h}), 24 \mathrm{~h}$ following the injections. C and D. Mean ( \pm S.E.M.) line crossing and rearing in the open field test, measured $4 \mathrm{~h}$ after the injections. E. Mean ( \pm S.E.M.) plasma corticosterone levels, measured in a separate sample of rats, $2 \mathrm{~h}$ after the injections. *Significantly different from the corresponding acutely injected saline group ( $p<.05)$. ${ }^{\dagger}$ Significantly different from the corresponding chronically treated saline group $(p<.05)$.

\section{DISCUSSION}

In the present study, administration of LPS was found to induce several sickness behavior symptoms. These findings replicate the results of many previous studies, which demonstrated that activation of the immune system by LPS, as well as other immune challenges, induces a reduction in appetite and body weight, suppres- 

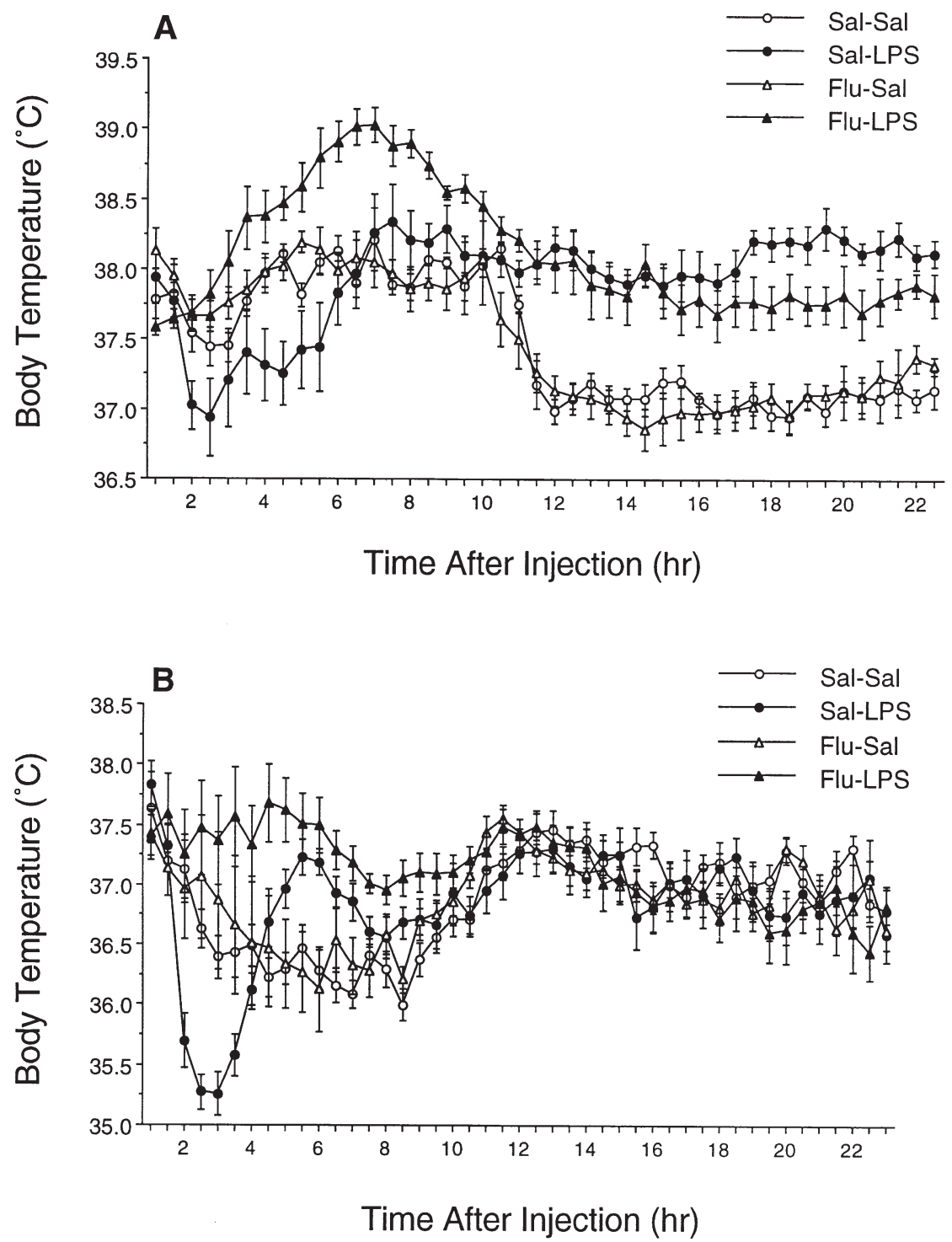

Figure 5. Effects of chronic fluoxetine administration on LPS-induced changes in body temperature in rats and mice. A. Two groups of rats received chronic treatment with either saline or fluoxetine $(10 \mathrm{mg} / \mathrm{kg}$, injected IP daily for $5 \mathrm{weeks})$. Baseline body temperature was recorded for 3 days before the experiment day, using a biotelemetric system, and did not differ between the groups. On the experiment day (at the beginning of the dark phase of the circadian cycle), rats within each chronic treatment group were injected with either saline or LPS $(100 \mu \mathrm{g} / \mathrm{kg})(n=6 /$ group$)$. Body temperature was recorded for an additional $23 \mathrm{~h}$, at 30-min intervals. B. Two groups of mice ( $n=8 /$ group) received chronic treatment with either saline or fluoxetine (10 mg/kg, injected IP daily for 5 weeks). Baseline body temperature was recorded for 3 days, using a biotelemetric system, and did not differ between the groups. On the experiment day (at the beginning of the light phase of the circadian cycle), all mice were injected with LPS $(50 \mu \mathrm{g} / \mathrm{kg})$ and body temperature was recorded for an additional $23 \mathrm{~h}$, at 30-min intervals.

sion of locomotor, exploratory, and social activity, fatigue and malaise, impairment in cognitive abilities, reduced libido and sexual behavior, and anhedonia (Anisman and Merali 1999; Dantzer et al. 1999; Maier and Watkins 1998; Yirmiya 1996; Yirmiya et al. 1994, 1999). Our results also demonstrate that LPS produced a marked depletion of CRH-41 ME content, which reflects its release into the portal vessels (Chappell et al. 1986), with a concomitant elevation in plasma corticosterone levels. This result is also consistent with many previous studies, which reported that LPS produces marked alterations in all components of the HPA axis, including the secretion of CRH, ACTH, and glucocorticoids (Tilders et al. 1994), as well as an impairment in the glucocorticoid negative feedback regulation of adrenocortical responses (Weidenfeld and Yirmiya 1996). Taken together, these behavioral and neuroendocrine symptoms resemble the characteristics of depression; therefore, we 

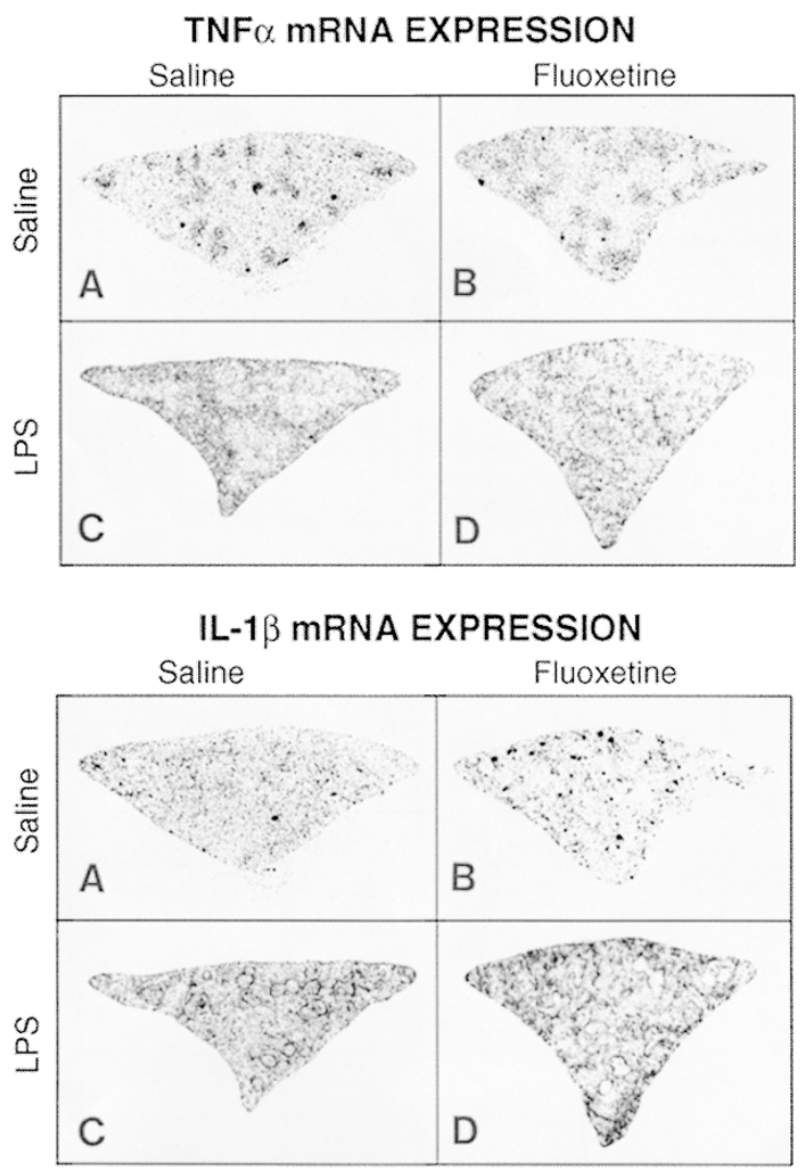

Figure 6. Effects of fluoxetine on LPS-induced splenic TNF $\alpha$ (Top) and IL-1 $\beta$ (Bottom) mRNA expression. Following chronic treatment with either saline or fluoxetine (10 $\mathrm{mg} / \mathrm{kg}$ injected IP daily for 5 weeks), rats were injected acutely with either saline or LPS $(100 \mu \mathrm{g} / \mathrm{kg})$. Spleens were removed $3 \mathrm{~h}$ postinjection and mRNA levels assessed by in situ hybridization. Presented are representative spleen sections taken from one animal from each of the following groups: chronic saline treatment/acute saline injection (A), chronic fluoxetine treatment/acute saline injection (B), chronic saline treatment/acute LPS injection (C), chronic fluoxetine treatment/acute LPS injection (D).

have recently argued that LPS (and probably other immune challenges) produces a depressive-like episode in animals, which is similar to the syndrome of "depression due to a general medical condition" in humans (Yirmiya 1996, 1997; Yirmiya et al. 1999).

In support of this hypothesis, we have previously demonstrated that chronic, but not acute, treatment with imipramine attenuated LPS-induced reduction in food consumption, body weight, social exploration, open field activity, and saccharin preference (Yirmiya 1996). A similar attenuation of LPS-induced sickness behavior has been recently reported following chronic administration of the TCA desipramine, but not the SSRI paroxetine or
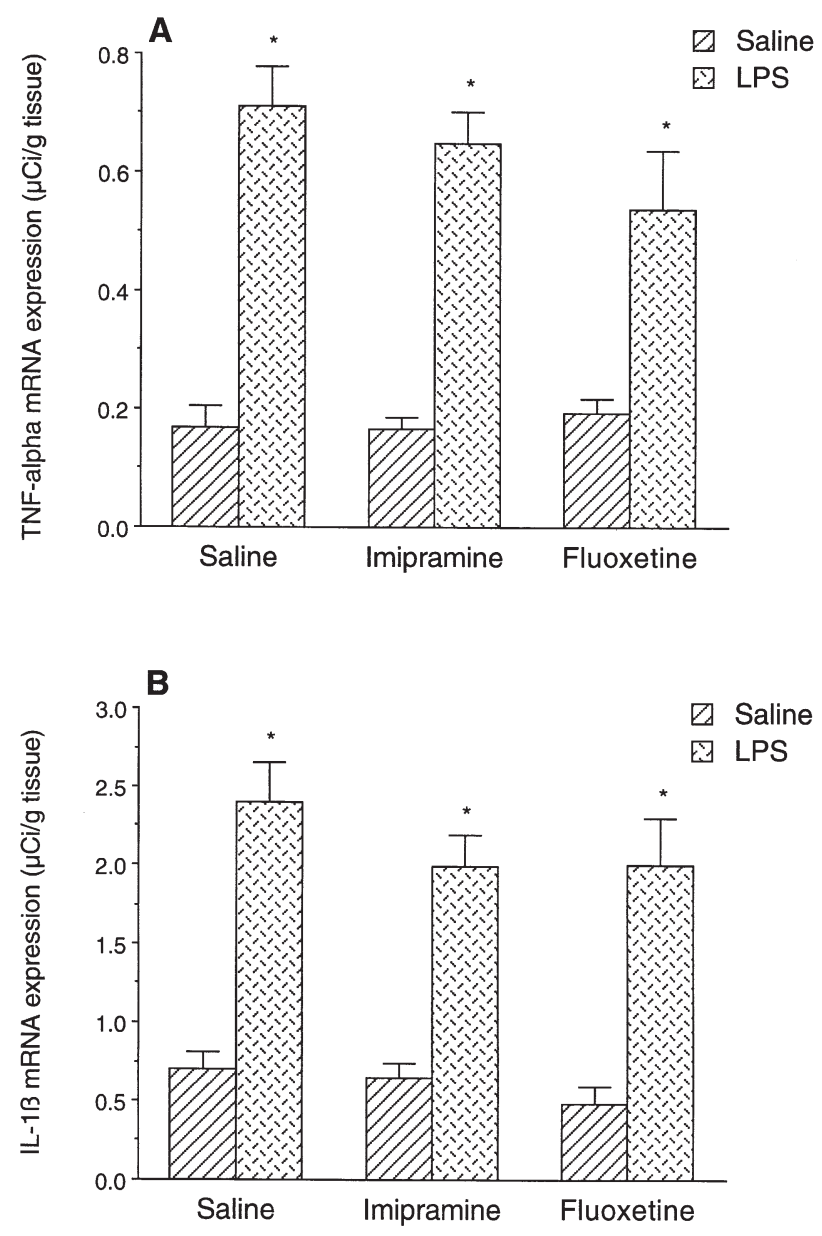

Figure 7. Effects of chronic treatment with fluoxetine, imipramine or saline on LPS-induced expression of TNF $\alpha$ and IL-1 $\beta$. The figure summarizes the quantitative results of individual sections (such as those presented in Figure 6). Nine sections were quantified for each animal for each cytokine. The results represent the mean ( \pm S.E.M.) of seven rats/group. *Significantly different from the corresponding acutely injected saline group $(p<.05)$.

the selective norepinephrine reuptake inhibitor venlafaxine (Shen et al. 1999). The results of the present study indicate that chronic treatment with the SSRI fluoxetine can attenuate LPS-induced anorexia and body-weight loss. However, in contrast with our previous findings with imipramine, fluoxetine had no effect on LPS-induced suppression of open field activity. The results also indicate that LPS-induced adrenocortical activation was attenuated to about the same degree by chronic treatment with either fluoxetine or imipramine. Taken together, these findings suggest that whereas chronic treatment with TCAs can effectively attenuate LPS-induced sickness behavior symptoms, SSRIs have more limited and variable effects on sickness behavior, but can be at least as effective as TCAs in attenuating the effects of LPS on the HPA axis.

LPS induces many changes within the brain, includ- 
ing alterations in monoaminergic systems (e.g., secretion of norepinephrine and serotonin) and CRH levels, which are considered as the main targets for antidepressants' therapeutic actions. With respect to their effects on behavioral parameters, the fact that TCAs seem to be superior to SSRIs (Shen et al. 1999; Yirmiya 1996, and the results of the present study) suggests that antidepressant-induced changes in the noradrenergic system may be more important. However, the lack of information on the neurochemistry of LPS-induced sickness behavior does not allow speculation on the specific role of each monoamine. For the HPA activation, which seemed to be equally affected by fluoxetine and imipramine, serotonergic mechanisms are probably critical (although noradrenergic mechanisms may still play a role) for the following reasons. First, serotonergic mechanisms are critically involved in LPS-induced pituitary adrenal activation (Givalois et al. 1999; Guo et al. 1996). Second, chronic fluoxetine induces desensitization of hypothalamic 5-HT-1A receptors and attenuates the pituitary-adrenal response to an acute serotonergic agonist (Raap et al. 1999). Thus, following chronic antidepressant treatment, LPS-induced serotonin secretion probably results in less HPA activation. Another system that is markedly altered following chronic antidepressant treatment is the HPA axis. For example, following long (8 weeks), but not short (2 weeks) treatment with either fluoxetine or imipramine, CRH mRNA was decreased by $30-48 \%$ in the hypothalamic PVN (Brady et al. 1991, 1992). Moreover, chronic treatment with fluoxetine, as well as other antidepressants, significantly elevated the levels of glucocorticoid receptors in the hippocampus (Brady et al. 1991, 1992), which normally mediate the negative feedback response to stress-induced activation of the HPA axis (Sapolsky et al. 1984). Finally, our results are in agreement with previous studies in experimental animals (Reul et al. 1993) and in healthy humans (Michelson et al. 1997), which reported that chronic treatment with antidepressants markedly attenuated the pituitary-adrenal response to stressful or pharmacological challenges. Although the role of $\mathrm{CRH}$ in mediating the anorexic effects of LPS has not been studied directly, there are indications that CRH mediates the anorexic effects of IL-1 (Bluthe et al. 1992; Uehara et al. 1989). Moreover, ample evidence indicates that CRH mediates LPS-induced adrenocortical activation (Tilders et al. 1994). Thus, it may be suggested that fluoxetine-induced attenuation of CRH neuronal activation is involved in the reduction of LPS-induced anorexia and adrenocortical activation.

We have previously reported that, in contrast to the suppressive effect of chronic imipramine on LPSinduced sickness behavior, acute administration of imipramine had no effect (Yirmiya 1996). It is difficult to reach a similar conclusion with respect to fluoxetine, because, in contrast to imipramine, acute fluoxetine by itself produced marked sickness behavior and elevation of corticosterone levels. These findings are consistent with the results of previous studies, in which marked reduction of food intake, body weight, and motor activity (McGuirk et al. 1992; Heisler et al. 1999), as well as elevated corticosterone levels (Bianchi et al. 1994; Duncan et al. 1998) were found following acute fluoxetine administration. In the present study, animals that were acutely injected with fluoxetine did not exhibit further changes in sickness behavior and corticosterone secretion following LPS (with the exception of LPS-induced decrease of body weight in fluoxetine-treated rats). However, these findings may represent the fact that for most parameters the effects of fluoxetine were so large that further alterations by LPS were not possible. This situation is different from the experiments with chronic treatment, in which fluoxetine by itself had only minimal effects, and LPS produced less anorexia, bodyweight loss, and corticosterone secretion in fluoxetinethan in saline-treated rats. Thus, any direct comparison between the effects of acute and chronic fluoxetine treatments is problematic. It should be noted that although the effects of acute fluoxetine are similar to those of other acute stressors, the effects of chronic fluoxetine treatment on the responsiveness to LPS cannot be attributed to chronic stress; whereas, exposure to chronic stress facilitates the adrenocortical response to a novel acute stressor (e.g., Marti et al. 1994), such as LPS, chronic fluoxetine treatment attenuated this response.

In agreement with previous reports on the effects of LPS on body temperature in rodents (Leon et al. 1999; Paul et al. 1999; Saper 1998; Wang et al. 1997; Yirmiya et al. 1994), we report here that in control rats and mice, LPS produced a biphasic effect on body temperature, with an initial hypothermia, followed by a febrile phase. In both strains, chronic treatment with fluoxetine completely abolished the hypothermic phase. In fluoxetine-treated rats, and to a lesser extent also in mice, the hyperthermic response was facilitated in time and larger than in controls. It is possible that this effect on hyperthermia is secondary to the blockade of the hypothermic response; that is, without the balancing effect of hypothermic mechanisms, the hyperthermia is facilitated in time and more pronounced. This interpretation is supported by the finding that in fluoxetine-treated rats, LPS-induced hyperthermia was facilitated in time and more pronounced during the initial few hours, but not at the later time points. LPS-induced hypothermia involves reduced thermogenesis by macrophagedependent (Derijk et al. 1994), nonvagal (Romanovsky et al. 1997) peripheral (Saper 1998) mechanisms. Several mediators have been proposed to be involved in LPSinduced hypothermia, including prostaglandins (Derijk et al. 1994; Wang et al. 1997), leukotriens (Paul et al. 1999), IL-10 (Leon et al. 1999), TNF $\alpha$ and vasopressin (Derijk and Berkenbosch 1994; Saper 1998). There is 
very little information on effects of antidepressants in general and fluoxetine in particular on these mediators. The results of the present study demonstrate that chronic fluoxetine treatment did not affect splenic $\mathrm{TNF} \alpha$ production. This finding is not consistent with an involvement of TNF $\alpha$ in fluoxetine's effect, although it does not rule out an effect of fluoxetine on LPS-induced $\mathrm{TNF} \alpha$ production in other peripheral and central tissues, which could still modulate the changes in body temperature. In previous research, chronic fluoxetine treatment resulted in reduced CSF concentrations of vasopressin in depressed patients (De-Bellis et al. 1993), as well as a reduction in hypothalamic vasopressin secretion in rats (Altemus et al. 1992). Together, these findings suggest that a reduction in vasopressin secretion is a possible mechanism for the effects of fluoxetine on the hypothermic response to LPS. To gain better understanding, future research should examine the effects of antidepressants on other mediators of LPS-induced changes in body temperature.

The effects of antidepressants on the responsiveness to LPS may be mediated by changes in immune response to LPS (particularly reduced production of cytokines), and/or by alterations in neurochemical systems that mediate the effects of LPS (and the cytokines that are secreted following its administration) within the brain. As a first step in elucidating these mechanisms, we examined the effects of fluoxetine and imipramine on the induction of splenic cytokines following LPS administration. Our findings indicate that neither antidepressant attenuated LPS-induced expression of TNF $\alpha$ and IL-1 $\beta$ mRNA in the spleen. These findings demonstrate that in contrast with the suppressive effects of antidepressants on cytokine production in vitro (Sommer et al. 1995; Xia et al. 1996), chronic treatment with antidepressants in vivo has no effect on LPSinduced production of cytokines in the spleen. Obviously, this finding does not preclude the possibility that antidepressants produce some of their effects by modulating the cytokine response for the following reasons. First, the effects of antidepressants were examined only with respect to splenic cytokine production. It is still possible that production in other peripheral tissues, such as liver cells, endothelial cells, peritoneal macrophages, and circulating macrophages, may have been affected. Second, mediators other than TNF $\alpha$ and IL-1 $\beta$ could be affected by antidepressants. For example, we have recently reported preliminary findings demonstrating reduced LPS-induced splenic inducible nitric oxide synthase (iNOS) mRNA expression (Yirmiya et al. 1999). Third, the present results were obtained at one time point ( $3 \mathrm{~h}$ postinjection). Responsiveness at other phases of the cytokine induction process could still be affected by antidepressants. Fourth, antidepressants may produce their effects on stimulated cytokine production in the brain and not in the periphery. Indeed, there is evidence for differential regulation of peripheral and central cytokine production following LPS administration (Sacoccio et al. 1998). Thus, in future research, the effects of antidepressants on LPS-induced production of brain cytokines should be assessed.

Many medical conditions are associated with a high prevalence of depression (Evans et al. 1996; LaghrissiTode et al. 1996), and a high incidence of antidepressant drug use (Egberts et al. 1997). Chronic treatment with antidepressants, including fluoxetine, has been found to be effective in alleviating the depression associated with multiple sclerosis (Schiffer and Wineman 1990), stroke (Lauritzen et al. 1994), HIV infection (Rabkin et al. 1994), cancer (Razavi et al. 1996), and neurodegenerative diseases (Alexopoulos 1996). Because these medical conditions are also associated with dramatic immune activation and cytokine secretion (Dinarello and Wolff 1993; Rothwell et al. 1996; Yirmiya et al. 1999), it may be suggested that at least part of the effects of fluoxetine (and possibly other antidepressants) in these conditions is in attenuating sickness behavior symptoms.

\section{ACKNOWLEDGMENTS}

The authors thank Edna Cohen, Roee Canaan, Inbal Goshen, and Anna Itzik for their help in running the experiments. This work was supported by Grant 94-204 from the United-StatesIsrael Binational Science Foundation, by a grant from the Milton Rosenbaum Foundation for Psychiatric Research, and by the Center for Research on Pain, The Hebrew University of Jerusalem. RY is a member of the Eric Roland Center for Neurodegenerative diseases.

\section{REFERENCES}

Alexopoulos GS (1996): The treatment of depressed demented patients. J Clin Psychiat 57:14-20

Altemus M, Cizza G, Gold PW (1992): Chronic fluoxetine treatment reduces hypothalamic vasopressin secretion in vitro. Brain Res 593:311-313

Anisman H, Merali Z (1999): Anhedonic and anxiogenic effects of cytokine exposure. In Dantzer R, Wollman EE, Yirmiya R (eds), Cytokines, Stress, and Depression. New York, Kluwer Academic/Plenum Publishers, pp 199-233

Bianchi M, Sacerdote P, Panerai, AE (1994): Fluoxetin reduces inflammatory edema in the rat: Involvement of the pituitary-adrenal axis. Eur J Pharmacol 263:81-84

Bianchi M, Rossoni G, Sacerdote P, Panerai AE, Berti F (1995): Effects of clomipramine and fluoxetin on subcutaneous carragenin-induced inflammation in the rat. Inflammation Res 44:466-469

Bluthe RM, Crestani F, Kelley KW, Dantzer R (1992): Mechanisms of the behavioral effects of interleukin 1. Role of prostaglandins and CRF. Ann NY Acad Sci 650:268-275 
Brady LS, Whitfield HJ, Fox RJ, Gold PW, Herkenham M (1991): Long-term antidepressant administration alters corticotropin-releasing hormone, tyrosine hydroxylase, and mineralocorticoid receptor gene expression in rat brain. Therapeutic implications. J Clin Invest 87:831-837

Brady, LS, Gold PW, Herkenham, M, Lynn, AB, Whitfield, HJ (1992): The antidepressants fluoxetine, idazoxan, and phenelzine alter corticotropin-releasing hormone and tyrosine hydroxylase mRNA levels in rat brain: Therapeutic implications. Brain Res 572:117-125

Chappell PB, Smith MA, Kilts CD, Bissetta G, Ritchie J, Anderson C, Nemeroff CB (1986): Alterations in corticotropin-releasing factor-like immunoreactivity in discrete rat brain regions after acute and chronic stress. J Neurosci 6: 2908-2914

Dantzer R, Wollman EE, Vitkovic L, Yirmiya R (1999): Cytokines and depression: Fortuitous or causative association? Mol Psychiat 4:328-332

De-Bellis MD, Gold PW, Geracioti TD, Listwak SJ, Kling MA (1993): Association of fluoxetine treatment with reductions in CSF concentrations of corticotropin-releasing hormone and arginine vasopressin in patients with major depression. Am J Psychiat 150:656-657

Derijk RH, Berkenbosch F (1994): Hypothermia to endotoxin involves the cytokine tumor necrosis factor and the neuropeptide vasopressin in rats. Am J Physiol 255:R9-R14

Derijk RH, Van-Kampen M, Van-Rooijen N, Berkenbosch F (1994): Hypothermia to endotoxin involves reduced thermogenesis, macrophage-dependent mechanisms, and prostaglandins. Am J Physiol 266:R1-R8

Dinarello CA, Wolff SM (1993): The role of interleukin-1 in disease. New Engl J Med 328:106-113

Duncan GE, Knapp DJ, Carson SW, Breese GR (1998): Differential effect of chronic antidepressant treatment on swim stress- and fluoxetine-induced secretion of corticosterone and progesterone. J Pharmacol Exp Ther 285:579-587

Egberts AC, Leufkens HG, Hofman A, Hoes AW (1997): Incidence of antidepressant drug use in older adults and association with chronic diseases: The Rotterdam Study. Int Clin Psychopharmacol 12:217-223

Evans DL, Staab J, Ward H, Leserman J, Perkins DO, Golden RN, Petito JM (1996): Depression in the medically ill: Management considerations. Depress Anx 4:199-208

Givalois L, Becq H, Siaud P, Ixart G, Assenmacher I, Barbanel G (1999): Serotonergic and suprachiasmatic nucleus involvement in the corticotropic response to systemic endotoxin challenge in rats. J Neuroendocrinol 11:629-636

Guo AL, Petraglia F, Criscuolo M, Ficarra G, Salvestroni C, Nappi RE, Trentini GP, Genazzani AR (1996): Adrenergic and serotonergic receptors mediate the immunological activation of corticosterone secretion in male rats. Gynecol Endocrinol 10:149-154

Heisler LK, Kanarek RB, Homoleski B (1999): Reduction of fat and protein intakes but not carbohydrate intake following acute and chronic fluoxetine in female rats. Pharmacol Biochem Behav 63:377-385

Johnson RW, Propes MJ, Shavit Y (1996): Corticosterone modulates the behavioral and metabolic effects of lipopolysaccharide. Am J Physiol 270:R192-R198
Kluger MJ (1991): Fever: Role of pyrogens and cryogens. Physiol Rev 71:93-127

Kubera M, Symbirtsev A, Basta-Kaim A, Borycz J, Roman A, Papp M, Claesson M (1996): Effect of chronic treatment with imipramine on interleukin-1 and interleukin-2 production by splenocytes obtained from rats subjected to chronic mild stress model of depression. Polish J Pharmacol 48:503-506

Laghrissi-Tode F, Pollock BG, Szanto K, Reynolds CF (1996): Depression and suicide in medically ill patients. Curr Opin Psychiat 9:137-140

Landmann R, Schaub B, Link S, Wacker HR (1997): Unaltered monocyte function in patients with major depression before and after three months of antidepressive therapy. Biol Psychiat 41:675-681

Lauritzen L, Bendsen BB, Vilmar T, Bendsen EB, Lunde M, Bech P (1994): Post-stroke depression: Combined treatment with imipramine or desipramine and mianserin. Psychopharmacology 114:119-122

Leon LR, Kozac W, Rudolph K, Kluger MJ (1999): An antipyretic role for interleukin-10 in LPS fever in mice. Am J Physiol 276:R81-R89

Li Q, Levy AD, Cabrera TM, Brownfield MS, Battaglia G, Van de Kar LD (1993): Long-term fluoxetine, but not desipramine, inhibits the ACTH and oxytocin responses to the 5-HT1a agonist, 8-OH-DPAT, in male rats. Brain Res 630:148-156

Maes M, Vandoolaeghe E, Van Hunsel F, Bril T, Demedts P, Wauters A, Neels H (1997): Immune disturbances in treatment-resistant depression: Modulation by antidepressive treatment. Human Psychopharmacol 12:153162

Maes M, Song C, Lin AH, Bonaccorso S, Kenis G, De-Jongh R, Bosmans E, Scharpe S (1999): Negative immunoregulatory effects of antidepressants: Inhibition of interferon-gamma and stimulation of interleukin-10 secretion. Neuropsychopharmacology 20:370-379

Maier SF, Watkins LR (1998): Cytokines for psychologists: Implications of bidirectional immune-to-brain communication for understanding behavior, mood, and cognition. Psych Rev 105:83-107

Marti O, Gavalda A, Gomez, F, Armario A (1994): Direct evidence for chronic stress-induced facilitation of the adrenocorticotropin response to a novel acute stressor. Neuroendocrinology 60:1-7

McGuirk J, Muscat R, Willner P (1992): Effects of chronically administered fluoxetine and fenfluramine on food intake, body weight, and the behavioral satiety sequence. Psychopharmacology-Berl 106:401-407

Michelson D, Misiewicz-Poltorak B, Raybourne RB, Gold PW, Sternberg EM (1994): Imipramine reduces the local inflammatory response to carrageenin. Agents Actions 42:25-28

Michelson D, Galliven E, Hill L, Demitrack M, Chrousos G, Gold PW (1997): Chronic imipramine is associated with diminished hypothalamic-pituitary-adrenal axis responsivity in healthy humans. J Clin Endocrinol Metab 82:2601-2606

Paul L, Fraifeld V, Kaplansky J (1999): Evidence supporting involvement of leukotrienes in LPS-induced hypothermia in mice. Am J Physiol 276:R52-R58 
Raap DK, Evans S, Garcia F, Li Q, Muma NA, Wolf WA, Battaglia G, Van-De-Kar LD (1999): Daily injections of fluoxetine induce dose dependent desensitization of hypothalamic 5-HT1A receptors: reductions in neuroendocrine responses to 8-OH-DPAT and in levels of $\mathrm{G}_{3}$ and Gi proteins. J Pharmacol Exp Ther 288:98-106

Rabkin JG, Wagner G, Rabkin R (1994): Effects of sertaline on mood and immune status in patients with major depression and HIV illness: An open trial. J Clin Psychiat 55:433-439

Razavi D, Allilaire JF, Smith M, Salimpour A, Verra M, Desclaux B, Saltel P, Piollet I, Gauvain-Piquard A, Trichard C, Cordier B, Fresco R, Guillibert E, Sechter D, Orth JP, Bouhassira M, Mesters P, Blin P (1996): The effect of fluoxetine on anxiety and depression symptoms in cancer. Acta Psychiatr Scan 94: 205-210

Reul JMHM, Stec I, Soder M, Holsboer F (1993): Chronic treatment of rats with antidepressant amitriptyline attenuates the activity of the hypothalamic-pituitaryadrenocortical system. Endocrinology 133:312-320

Romanovsky AA, Simons CT, Szekely M, Kulchitsky VA (1997): The vagus nerve in the thermoregulatory response to systemic inflammation. Am J Physiol 273:R407-R413

Rothwell NJ, Luheshi G, Toulmond S (1996): Cytokines and their receptors in the central nervous system: Physiology, pharmacology, and pathology. Pharmacol Therapeu 69:85-95

Sacoccio C, Dornand J, Barbanel G (1998): Differential regulation of brain and plasma TNF $\alpha$ produced after endotoxin shock. Neuroreport 9:309-313

Saper CB (1998): Neurobiological basis of fever. Ann NY Acad Sci 856:90-94

Sapolsky RM, Krey LC, McEwen BS (1984): Glucocorticoidsensitive hippocampal neurons are involved in terminating the adrenocortical stress response. Proc Natl Acad Sci USA 81:6174-6177

Schiffer RB, Wineman NM (1990): Antidepressant pharmacotherapy of depression associated with multiple sclerosis. Am J Psychiat 147:1493-1497

Seidel A, Arolt V, Hunstiger M, Rink L, Behnisch A, Kirchner, H (1996): Major depressive disorder is associated with elevated monocyte counts. Acta Psychiat Scand 94:198-204

Shen Y, Connor TJ, Kelly JP, Leonard BE (1999): Differential effect of chronic antidepressant treatment on lipopolysaccharide-induced depressive-like behavioral symptoms in the rat. Life Sci 65:1773-1786

Sluzewska A, Rybakowski J, Laciak M, Mackiewicz A, Sobieska M, Wiktorowicz K (1995): Interleukin-6 serum levels in depressed patients before and after treatment with fluoxetine. Ann NY Acad Sci 762:474-476

Sommer N, Loschmann PA, Northoff GH, Weller M, Steinbrecher A, Steinbach JP, Lichtenfels R, Meyermann R, Riethmuller A, Fontana A, Dichgans J, Martin R (1995): The antidepressant rolipram suppresses cytokine production and prevents autoimmune encephalomyelitis. Nature Med 1:244-248

Song C, Leonard BE (1994): An acute phase protein response in the olfactory bulbectomized rat: Effect of sertraline treatment. Med Sci Res 22:313-314
Tilders FJH, Derijk RH, Vandam AM, Vincent VAM, Schotanus K, Persoons JHA (1994): Activation of the hypothalamus-pituitary-adrenal axis by bacterial endotoxinsRoutes and intermediates. Psychoneuoendocrinology 19:209-232

Uehara A, Sekiya C, Takasugi Y, Namiki M, Arimura A (1989): Anorexia-induced by interleukin 1: Involvement of corticotropin-releasing factor. Am J Physiol 257:R613-R617

Wang J, Ando T, Dunn AJ (1997): Effect of homologous interleukin-1, interleukin-6, and tumor necrosis factoralpha on the core body temperature of mice. Neuroimmunomodulation 4:23-236

Weidenfeld J, Yirmiya R (1996): Effect of bacterial endotoxin on the glucocorticoid feedback regulation of adrenocortical response to stress. Neuroimmunomodulation 3: 352-357

Weizman R, Laor N, Podliszewski E, Notti I, Djaldetti M, Bessler H (1994): Cytokine production in major depressed patients before and after clomipramine treatment. Biol Psychiat 35:42-47

Willner P (1997): Validity, reliability, and utility of the chronic mild stress model of depression: a 10-year review and evaluation. Psychopharmacology 134:319329

Xia Z, Depierre JW, Nassberger L (1996): Tricyclic antidepressants inhibit IL-6, IL-1 $\beta$ and TNF- $\alpha$ release in human blood monocytes and IL-2 and interferon- $\gamma$ in T-cells. Immunobiology 34:27-37

Yirmiya R, Rosen H, Donchin O, Ovadia H (1994): Behavioral effects of lipopolysaccharide in rats: Involvement of endogenous opioids. Brain Res 648: 80-86

Yirmiya R (1996): Endotoxin produces a depressive-like syndrome in rats. Brain Res 711:163-174

Yirmiya R (1997): Behavioral and psychological effects of immune activation: Implications for "depression due to a general medical condition." Curr Opin Psychiat 10:470-476

Yirmiya R, Barak O, Avitsur R, Gallily R, Weidenfeld J (1997): Intracerebral administration of Mycoplsma fermentans produces sickness behavior: Role of prostaglandins. Brain Res 749:71-81

Yirmiya R, Weidenfeld J, Pollak Y, Morag M, Morag A, Avitsur R, Barak O, Reichenberg A, Cohen E, Shavit Y, Ovadia H (1999): Cytokines, "depression due to a general medical condition" and antidepressants drugs. In Dantzer R, Wollman EE, Yirmiya R (eds), Cytokines, Stress, and Depression. New York, Kluwer Academic/ Plenum Publishers, pp 283-316

Zhang Y, Raap DK, Garcia F, Serres F, Ma Q, Battaglia G, Van de Kar LD (2000): Long-term fluoxetine produces behavioral anxiolytic effects without inhibiting neuroendocrine responses to conditioned stress in rats. Brain Res 855:58-66

Zhu J, Bengtsson BO, Mix E, Thorell LH, Olsson T, Link H (1994): Effect of monoamine reuptake inhibiting antidepressants on major histocompatibility complex expression on macrophages in normal rats and rats with experimental allergic neuritis (EAN). Immunopharmacology 27:225-244 